\title{
O NOVO PARADIGMA TECNOLÓGICO DO SETOR FINANCEIRO NACIONAL: A IMPLANTAÇÃO DO OPEN BANKING NO BRASIL'1
}

Eric Jardim Cavalcante ${ }^{2}$

\section{SINOPSE}

O Banco Central do Brasil (BCB) vem introduzindo uma série de transformaçóes operacionais e tecnológicas nos últimos anos visando adotar sua estratégia da Agenda $\mathrm{BC}+$, que é a agenda estrutural para promover mudanças e evoluções no Sistema Financeiro Nacional (SFN) em termos de inclusão financeira, modernização de arcabouço legal, aumento de sua eficiência tecnológica e operacional e implantação de estímulos para promoção de um crédito mais barato. Nesse bojo, uma das medidas mais recentes é a implantaçáo do open banking, que estimula a concorrência e a redução do custo do crédito e que muda o paradigma tecnológico do mercado e dos serviços prestados pelo SFN.

Palavras-chave: open banking; custo de crédito; Banco Central do Brasil; application programming interfaces (APIs); tecnologia bancária.

\section{INTRODUÇÃO}

O open banking não é uma experiência única no mundo. Embora as premissas sejam bastante semelhantes entre os países, o open banking é um conceito amplo que não se limita à ideia de produto, processo, método ou sistema. Ao implantar esse conceito, o Brasil estará na vanguarda dos países que se adequam às tecnologias emergentes, particularmente às revoluçóes que vêm ocorrendo com o surgimento das fintechs e dos novos produtos e métodos de pagamentos decorrente das tecnologias de blockchain e criptomoedas.

O open banking, ou sistema financeiro aberto, está assentado sob os pilares da eficiência do Sistema Financeiro Nacional (SFN) e da oferta de crédito mais barato. Ele foi desenhado para propiciar o compartilhamento padronizado de dados e serviços por meio de application programming interfaces (APIs) ${ }^{3}$ por parte de instituiçóes autorizadas pelo Banco Central do Brasil (BCB). No caso de dados de clientes, pessoa física (PF) ou jurídica (PJ), é o cliente que decidirá quando e com quem ele deseja compartilhá-los no escopo do open banking.

Uma das principais características do open banking é permitir a ampliação da oferta de produtos e serviços, estimulando a competitividade entre bancos, fintechs e outros negócios relacionados. Uma das motivaçóes para sua implantação é que o custo do crédito bancário no Brasil é um dos maiores do mundo. Entre outros fatores, isso decorre principalmente da alta concentração bancária brasileira, da baixa mobilidade de clientes entre instituições financeiras e do alto custo do crédito embutido nas taxas de juros.

2. Pesquisador do Subprograma de Pesquisa para o Desenvolvimento Nacional (PNPD) na Diretoria de Estudos e Políticas Setoriais de Inovação e Infraestrutura (Diset) do Ipea. E-mail: <eric.cavalcante@ipea.gov.br>.

3. 0 propósito das APIs é o de simplificar o desenvolvimento de programas e aplicações, através da abstração dos diversos elementos que compõem um software. Isso permite que o desenvolvedor não precise saber detalhadamente a implementação de todas as partes que compõem um sistema, mas sim, precisará saber como utilizar os serviços fornecidos pelas APIs de seu interesse e como se dará a interação destas com os outros elementos de seu software. 
Outra motivação reside na facilidade que o consumidor terá de gerenciar suas contas e serviços de forma unificada mesmo quando o produto pertencer à uma instituição diferente da que ele possui relacionamento. Através de uma plataforma única, os clientes poderão acessar inúmeras informaçóes acerca do seu histórico de transaçóes, perfil de crédito e outras informaçóes a partir do estoque de dados gerado ao longo do tempo de seu relacionamento com as instituiçôes bancárias do SFN. Quando o cliente possuir contas em mais de uma instituição bancária, suas visualizaçôes de saldos, produtos, transaçôes e manipulação de finanças poderão ser realizadas em um canal único que compartilha todas as suas informaçóes, mas que está acessível apenas ao usuário ou às instituiçóes que o usuário autorizar o acesso.

Embora o open banking seja uma mudança de paradigma devido ao seu amplo espectro, inúmeros avanços ou modificaçóes que são feitos nos demais países já fazem parte de mudanças que foram implantadas no Brasil ao longo do tempo. Desta forma, é importante destacar as características e experiências dos países que já adotaram este conceito como uma prévia do que pode ser esperado ou aprimorado para o caso brasileiro.

\section{OPEN BANKING NO MUNDO}

Diferentemente dos demais países, é comum que os bancos no Brasil sejam de natureza múltipla, com carteiras que oferecem seguros, previdência, títulos mobiliários etc., além dos tradicionais serviços bancários. O sistema brasileiro também é bastante avançado tecnologicamente, em grande parte devido à necessidade de evolução durante os períodos de instabilidade macroeconômica das décadas passadas. Muitos países que já adotaram o open banking o estão fazendo em fases, e muitas dessas fases são desafios que já foram superados pelo SFN. Como o conceito open banking não é estritamente definido, a seguir tem-se o andamento e as características das fases em que estão os países que já começaram ou planejam sua implantação.

\subsection{União Europeia}

A União Europeia foi umas das primeiras a regulamentar esse assunto e, em 2018, colocou em vigor a regulamentação conhecida como nova diretiva do setor de pagamentos financeiros (ou PSD2), a qual estabelecia obrigaçóes para as instituiçốes financeiras abrirem suas APIs para acesso por outras instituições financeiras e não financeiras.

Segundo dados do openbankingtracker, ${ }^{4}$ o número de APIs abertas para as cinco principais economias da União Europeia é de 71 para a Alemanha, 89 para a França, 57 para a Itália, 46 para a Espanha e 52 para a Holanda. Estes números estão bem à frente dos da Suíça, que não faz parte da União Europeia mas que possui tradição na prestação de serviços financeiros de longa data. Entretanto, ainda estão atrás de praças como a do Reino Unido, que possui 166 APIs abertas.

\subsection{Reino Unido}

Atualmente, o Reino Unido é considerado o benchmark de open banking no mundo, com mais de 88 prestadores de serviços e cerca de 166 APIs abertas prestando serviços para milhóes de clientes. O escopo do open banking britânico é abrangente, contando com o compartilhamento de dados e produtos dos clientes, bem como a iniciaçáo de pagamentos e transferências entre contas.

4. Disponível em: <https://openbankingtracker.com/countries>. 


\subsection{Austrália}

O open banking da Austrália surgiu em meados de 2019 com foco exclusivo no compartilhamento de todas as principais informaçôes financeiras dos clientes, como contas bancárias, cartôes de crédito, empréstimos, seguros, financiamento, entre outros. Espera-se que o open banking seja totalmente implementado até novembro de 2022; atualmente são 33 APIs abertas.

\subsection{Hong Kong}

O open banking em Hong Kong deu-se por fases; a primeira delas envolveu o compartilhamento de dados dos bancos sobre produtos e serviços; a abertura dos dados dos preços dos serviços (taxas, tarifas, ofertas) deu-se no início de 2019, e já é permitida a comparação entre instituiçóes em razão das APIs abertas; são nove APIs disponibilizadas até o momento, segundo dados do openbankingtracker.

Inúmeras outras medidas têm sido adotadas no mundo, e o BCB produziu um mapa que busca reunir brevemente o estágio e as característica da implantação do open banking pelo mundo, sobretudo em relação a aspectos regulatórios e grau de maturidade. A figura 1 resume essas informaçóes.

\section{FIGURA 1}

Visão global de desenvolvimento do open banking

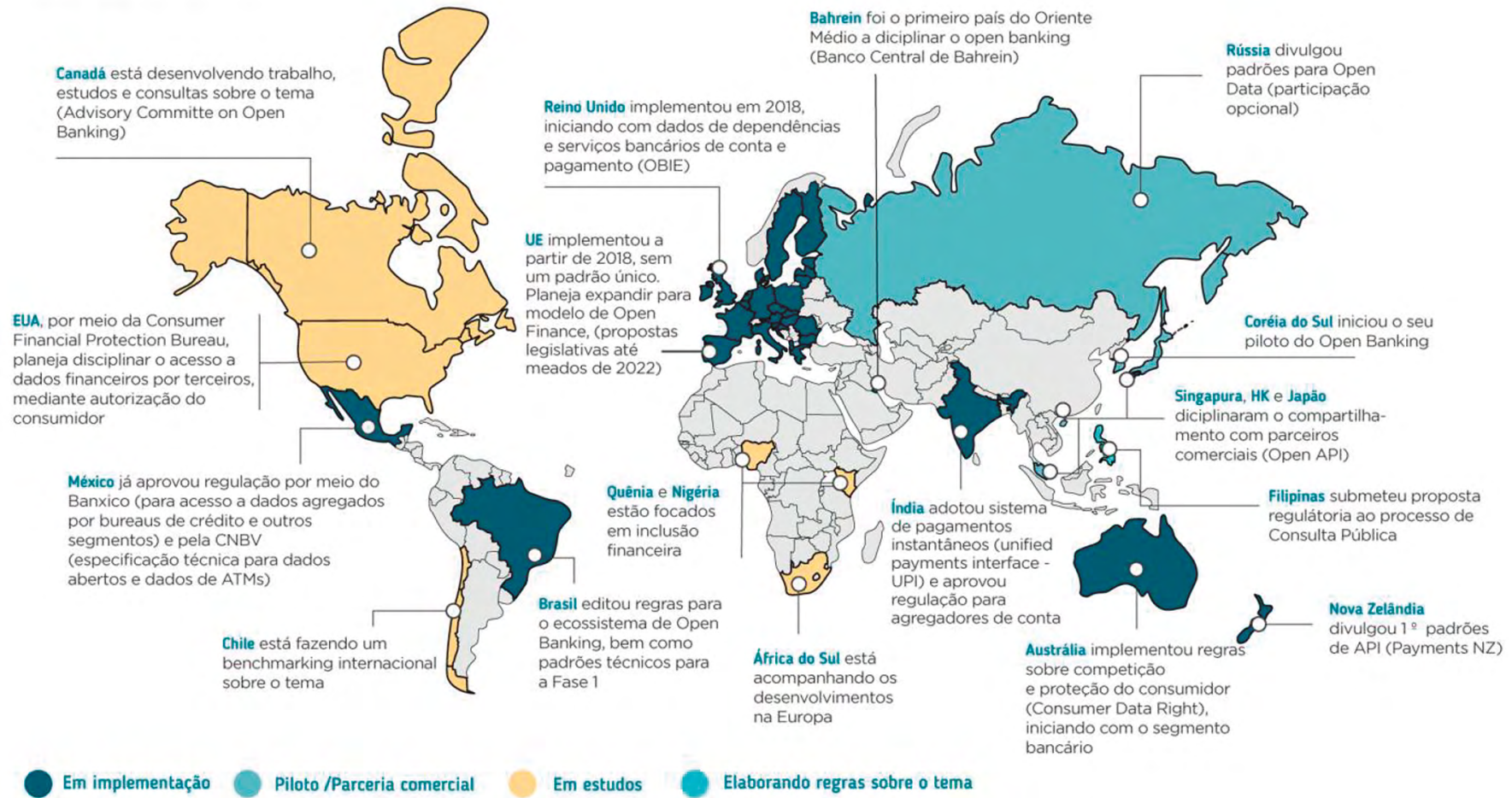

Fonte: $\mathrm{BCB}$.

Obs.: Figura cujos leiaute e textos não puderam ser padronizados e revisados em virtude das condições técnicas dos originais (nota do Editorial). 


\section{OPEN BANKING NO BRASIL}

No Brasil, a jornada de open banking foi iniciada em 2020, a partir da organização do BCB junto com empresas e associaçóes participantes do mercado financeiro e de pagamentos. A implementaçâo foi dividida em quatro fases, expostas a seguir, sendo que, em cada uma delas, serão incluídos novos dados que poderáo ser compartilhados.

1) Open data das instituiçôes financeiras: com início em 1ํ de fevereiro de 2021, nessa fase há a disponibilização dos dados entre as próprias instituiçôes financeiras, que deverão apresentar as informaçóes de seus canais de atendimento (locais físicos e virtuais) e de seus produtos e serviços, incluindo as taxas e tarifas de cada produto e serviço ofertado.

2) Dados cadastrais e transacionais dos consumidores: com início previsto para 13 de agosto de 2021, essa fase permitirá que o consumidor, mediante consentimento, possa compartilhar seus dados (cadastros, transaçōes em conta, informações sobre cartôes e operaçôes de crédito) com instituições de sua escolha e preferência. Caso deseje, o consumidor poderá revogar o consentimento desse compartilhamento a qualquer momento.

3) Serviços financeiros para consumidores: com data de implementação prevista para 30 de agosto de 2021, os consumidores terão acesso a serviços financeiros, como pagamentos e encaminhamento de propostas de crédito, sem a necessidade de acessar os canais das instituiçóes financeiras com as quais eles já têm relacionamento.

4) Ampliaçáo de dados, produtos e serviços: com implementaçáo prevista para 15 de dezembro de 2021, a quarta fase prevê a inclusão de novos dados que poderão ser compartilhados, além de novos produtos e serviços, tais como contrataçáo de operaçôes de câmbio, investimentos, seguros e previdência privada.

Cabe destacar que a ideia é que o open banking evolua para que mais dados, produtos e serviços sejam incorporados, levando a uma evolução em um sentido de open finance.

\subsection{Principais vantagens}

Entre as principais expectativas destacam-se a ampliação do poder de escolha do consumidor, a melhora na eficiência e na competitividade do mercado, o aumento das oportunidades de novos modelos de negócios, a inclusão financeira e a transparência em relação aos produtos e serviços. As vantagens foram resumidas a seguir.

1) Competitividade: o open banking facilita a entrada de produtos e serviços para os consumidores, melhora o atendimento ao cliente e melhora os serviços prestados, devido a maior competiçáo entre as instituiçóes financeiras.

2) Padronização: em um único ambiente se terá todas as informaçóes, os produtos e os serviços de diferentes instituiçôes a fim de facilitar o uso de seus dados. Permitindo aos seus usuários soluçôes mais pertinentes, melhorando a oferta de produtos e serviços. Com isso trazendo facilidades para novos clientes, empreendedores, desenvolvedores, entre outros.

3) Satisfação do consumidor: com o aumento da oferta, a burocracia diminui, facilitando as migraçôes para outras instituiçóes.

4) Redução dos custos bancários: se não há a obrigação de se manter preso a um estabelecimento, a tendência é que essas instituiçóes comecem a reduzir os custos com o objetivo de atrair mais clientes. Esse benefício já pode ser notado com a criação de contas digitais que não cobram taxas de manutenção dos usuários. 


\subsection{Principais desafios/desvantagens}

Nesse pequeno contexto, um dos primeiros desafios da regulação ou autorregulação bancária para implementação do open banking está relacionada à tecnologia das interfaces. Esse ponto é central para que possa ocorrer o compartilhamento dos dados dos clientes e dos produtos e serviços das instituiçóes participantes com um padrão mínimo de qualidade e operabilidade. Aliada a padróes tecnológicos, menciona-se a segurança da informação e a proteção dos dados como o próximo desafio à regulamentação bancária em matéria de open banking. Resumem-se, a seguir, os desafios.

1) Resistência: algumas empresas do setor ainda são resistentes ao modelo, já que ainda não precisam compartilhar informaçôes com os concorrentes, mas, à medida que o processo avance e mais empresas sejam incluídas no rol de obrigatoriedade, isso poderá ser superado.

2) Segurança da informação: uma das prioridades será estabelecer controle e confiabilidade aos clientes para garantir a segurança dos dados, já que seráo expostos a outras instituiçóes mesmo com a permissão dos usuários.

3) Aumento do custo operacional das empresas: com o aumento de volume nas transaçóes entre as instituiçóes deve haver maior investimento por parte das instituiçóes nas suas equipes de treinamento, infraestrutura e tecnologia.

4) Competição: as empresas deverão se esforçar de forma elaborada para conseguir atrair clientes, com isso há um aumento dos gastos em marketing e tecnologia.

\section{BIBLIOGRAFIA COMPLEMENTAR}

CRUICKSHANK, A. How far has open banking come in Europe? ComputerWeekly.com, 29 Mar. 2021. Disponível em: <https://bit.ly/3hyvWuq>. Acesso em: 9 jun. 2021.

EVRIPIDOU, A. Consolidating the European open banking ecosystem. Finance Monthly, 17 Mar. 2021. Disponível em: <https://bit.ly/3wCI8P4>. Acesso em: 9 jun. 2021.

FEBRABAN - FEDERAÇÃO BRASILEIRA DE BANCOS. Open banking no contexto da Agenda BC\#. In: CONGRESSO FEBRABAN DE DIREITO BANCÁRIO, 15., 2019, São Paulo. Anais... São Paulo: Febraban, 2019. Disponível em: $<$ https://bit.ly/3AZDONm>. Acesso em: 9 jun. 2021.

GOETTENAUER, C. Open banking e o modelo de banco em plataforma: a necessidade de reavaliação da definição jurídica de atividade bancária. Revista da Procuradoria-Geral do Banco Central, v. 14, n. 1, p. 13-27, set. 2020. Disponível em: <https://bit.ly/3AXDrTp>. Acesso em: $1^{\circ}$ jun. 2021.

KAVAKAMA, J. Open banking: oportunidades, desafios e aprendizados. Noomis, 2 out. 2019. Disponível em: <https:// bit.ly/36CB5vf>. Acesso em: 9 jun. 2021.

OPEN banking: como o sistema muda o mercado financeiro. Conductor, 11 mar. 2021. Disponível em: <https://bit. ly/2U7iPaD>. Acesso em: 9 jun. 2021.

TAVEIRA, R. A Lei PSD2 obriga todos os bancos europeus a abrirem suas APIs, enquanto isso open banking está ganhando o mundo. Cryptoid, São Paulo, mar. 2018. Disponível em: < https://bit.ly/3wE8m3M>. Acesso em: 9 jun. 2021.

THE STATE of open banking in Australia in 2021. Fintechnews Singapore, 4 Feb. 2021. Disponível em: <https://bit. ly/3wHK2xQ>. Acesso em: 9 jun. 2021.

VEIGA, F. da S.; GIBRAN, S. M.; BONSERE, S. F. M. Open banking: expectativas e desafios para o mercado financeiro no Brasil. Administração de Empresas em Revista, v. 1, n. 15, p. 203-226, 2020. 


\section{SITES CONSULTADOS}

BCB - BANCO CENTRAL DO BRASIL. Open banking. Disponível em: <https://bit.ly/3wxgvqE>. Acesso em: 9 jun. 2021.

INFOMONEY. Open banking: o que é e como funciona? Disponível em: <https://bit.ly/3hCWYkl>. Acesso em: 9 jun. 2021. KPMG. Open banking - a visão da KPMG. Disponível em: <https://bit.ly/2T6q02e>. Acesso em: 9 jun. 2021.

LIGA INSIGHTS. Open banking: o que é, como funciona e as vantagens para o mercado. Disponível em: <https://bit. ly/3hzNruo>. Acesso em: 9 jun. 2021.

OPENBANKINGTRACKER. Open banking in Sweden. Disponível em: <https://bit.ly/3xFqwU7>. Acesso em: 9 jun. 2021. 